\title{
The protective role of 3-aminothiazolo[3- 2a]benzimadzole-2-carbonitrile against lung and colon injury induced by nitrosomorpholine in adult male albino rat
}

\author{
Hossam El-Din M. Omar ${ }^{1 *}$, Heba M. Saad El-Din ${ }^{2}$, Elham A. Abd-Allah ${ }^{1}$ and \\ Abdelwareth A. O. Sarhan ${ }^{3}$ \\ ${ }^{1}$ Physiology Laboratory, Zoology Department, Faculty of Science, Assiut University, Egypt, 71516, Egypt. \\ ${ }^{2}$ Histology Department, Faculty of Medicine, Assiut University, Egypt, 71516, Egypt. \\ ${ }^{3}$ Chemistry Department, Faculty of Science, Assiut University, Egypt, 71516, Egypt.
}

Accepted 11 June, 2012

\begin{abstract}
Nitrites and morpholine are ubiquitous environmental contaminants found in drinking water and food. NMOR can be formed endogenously from nitrite and morpholine. Increased levels of reactive oxygen species/ reactive nitrite species (ROS/RNS) are involved in the mechanism of NMOR toxicity. Certain antimicrobial, antifungal and antioxidant potential were observed in heterocyclic benzimidazole derivatives and dimethyl sulfoxide (DMSO). This study was designed to evaluate the biological potential of 3-aminothiazolo[3-2a]benzimadzole-2-carbonitrile in the protection of lung and colon tissues against the increased levels of ROS/RNS that are induced by administration of nitrite and morpholine in drinking water for 15 weeks. Forty adult male rats were categorized into 4 groups, 10 rats each. The results showed a significant increase in NO, lipid peroxidation (LPO), total peroxides (TPO), superoxide anion $\left(\mathrm{O}_{2}{ }^{-}\right)$and DNA fragmentation in lung and colon tissues of rats treated with nitrite and morpholine compared to the control group. Moreover, histological observation of the lung and colon tissues showed cell necrosis, increase in the leukocyte infiltration and blood vessel congestion. Immunostaining for inducible nitric oxide synthase (iNOS) showed positive reaction for lung and colon tissues. After the co-treatment of rats with DEMSO and 3-aminothiazolo[3-2a]benzimadzole-2carbonitrile, all the previous biochemical changes were reduced in addition to the relative improvement in the morphological changes of both lung and colon. In conclusion, the injury in lung and colon tissues induced by nitrite and morpholine may return to the increased production of ROS and to the alterations in the levels of antioxidants. Co-treatment of rats with 3-aminothiazolo[3-2a]benzimadzole-2carbonitrile and DMSO may protect them against nitrite and morpholine toxicity.
\end{abstract}

Key words: Nitrite, morpholine, nitrosomorpholine (NMOR), inducible nitric oxide synthase (iNOS), benzimidazole derivatives, dimethyl sulfoxide (DMSO), colon, lung, rat.

\section{INTRODUCTION}

The importance of considering chemical mixture exposure in dealing with environmental issues has recently become better recognized. Humans and domestic animals are clearly exposed concomitantly to several environmental carcinogens at low doses under normal conditions (Mumtazz et al., 1993). Occupational and environmental 
exposure to $\mathrm{N}$-nitroso compounds (NNC) represents a potential health hazard to humans (Kitano et al., 1997). Nitrites and secondary amines which represent precursors of NNC are contained in many kinds of common food and can react under acidic conditions in the stomach (Erkekoglu and Baydar, 2010). The secondary amine morpholine can be easily converted to nitrosomorpholine (NMOR) in the presence of nitrite both in vivo and in vitro (Mirvish, 1995). NMOR and their precursors in the environment in certain occupational location as well as their endogenous formation in the human body from dietary components are associated with an increased risk of gastrointestinal cancer (Hord et al., 2009).

Furthermore, NMOR causes the generation of reactive oxygen species/ reactive nitrite species (ROS/RNS), resulting in oxidative stress and cellular injury (Bartsch et al., 1989; Spiteller, 1996). However, organs that possess antioxidant defense system can react with ROS/RNS and neutralize them before they cause injury on vital cell components (Bansal et al., 2005). Nitric oxide (NO) that is produced from L-arginine by nitric oxide synthase (NOS) isoforms (neuronal, endothelial and inducible) may act as a protectant against cytotoxic stress or may enhance cytotoxicity when produced at elevated concen-tration (Wu and Cederbaum, 2006). Moreover, NO can react with superoxide anion to form peroxynitrite, which causes oxidative damage to DNA (Michel and Feron, 1997).

Thiazolo[3-2a]benzimidazole derivatives have been indicated as being associated with a wide range of biological properties, including antibacterial activity, hypoglycemic, antiviral and antitumor (Hjorth et al., 1994; Sekhar, 2009). DMSO as organic solvent can penetrate membranes without damaging them and could carry other compounds into a biological system; hence it is used as a drug delivery solvent (Geiss, 2001). The present study was designed to evaluate the biological activity of the 3aminothiazolo[3-2a]benzimadzole-2-carbonitrile and its solvent DMSO, in the protection of lung and colon tissues against oxidative stress induced by nitrite and morpholine as precursor of NMOR and to evaluate the role of inducible nitric oxide synthase (iNOS) in NMOR toxicity.

\section{MATERIALS AND METHODS}

\section{Experimental animals}

Forty male Sprague-Dawley rats of 140 to $160 \mathrm{~g}$ were obtained from the Animal House of the Faculty of Medicine, Assiut University, Assiut, Egypt. Rats were housed in cages and were kept in a room temperature about $30^{\circ} \mathrm{C}$ with normal light/dark cycle. They were allowed to acclimatize for one week before the experiment and they had ad libitum access to pelleted diet and water throughout the study. All experimental protocols held on animals were done according to regulations set by the Institutional Animal Care and approved by Assiut University.

\section{Chemicals}

3-Aminothiazolo[3-2a]benzimadzole-2-carbonitrile was synthesized by Sarhan et al. (2008). DMSO, Folin-Ciocalteu, phenol, diphenylamine, tetramethylpyrazine (TMP), xylenol orange, 1-chlor2,4-dinitrobenzol (CDNB), 5, 5'-dithiobis-(2-nitrobenzoic) acid (DTNB), iodonitrotetrazolium, a, $\alpha$-dipyridyl, vitamin $\mathrm{C}$, sodium dodecyl sulphate, thiobarbituric acid, epinephrine and diaminobenzidine tetrahydrochloride were purchased from Sigma Chemical Co. (St. Louis, MO, USA). Primary antibodies were purchased from BD Biosciences, San Diego, CA, USA. Avidin-biotinylated peroxidase complex reagent was purchased from Vector Laboratories, Burlingame, CA, USA, while isotype-matched mouse IgG2a was obtained from BD Biosciences, U.K. All other chemicals were of the highest purity commercially available

\section{Experimental design}

The rats were randomly divided into four groups, 10 rats each as follows: Group 1, control animals; Group 2, treated daily with sodium nitrite $(1 \mathrm{~g} / \mathrm{L})$ and morpholine $(2 \mathrm{ml} / \mathrm{L})$ in drinking water for 15 weeks according to Mirvish et al. (1976); Group 3: treated daily with sodium nitrite $(1 \mathrm{~g} / \mathrm{L})$ and morpholine $(2 \mathrm{ml} / \mathrm{L})$ and day after day with DMSO $(0.2 \mathrm{ml} / \mathrm{kg})$ as solvent for the 3-aminothiazolo[32a]benzimadzole-2-carbonitrile; Group 4, treated daily with sodium nitrite $(1 \mathrm{~g} / \mathrm{L})$ and morpholine $(2 \mathrm{ml} / \mathrm{L})$ and day after day with 3aminothiazolo[3-2a]benzimadzole-2-carbonitrile $\quad(2 \mathrm{mg} / \mathrm{kg}$ ) according to Spasov et al. (1999). All animals were exposed to similar volume of administration.

\section{Tissue preparation}

At the end of the treatment period, blood was collected under ether anesthesia and lung and colon were removed and washed in $0.1 \mathrm{M}$ phosphate buffer ( $\mathrm{pH} 7.4)$, then divided into two parts, a small part was used for histopathological and immunohistochemical studies and a larger part was immersed in liquid nitrogen and stored at $20^{\circ} \mathrm{C}$ for biochemical analysis. In brief, $10 \% \mathrm{w} / \mathrm{v}$ homogenate of lung and colon tissue was prepared in $0.1 \mathrm{M}$ phosphate buffer $(\mathrm{pH}$ 7.4) using IKA Yellow line DI homogenizer (18 Disperser, Germany). The homogenates were centrifuged at $10,000 \mathrm{~g}$ for $1 \mathrm{~h}$ at $4^{\circ} \mathrm{C}$ and the supernatant cytosols were used for subsequent biochemical assays.

\section{Biochemical measurements}

The total protein was measured by the method of Lowry et al. (1951). Lipid peroxides as thiobarbituric acid reactive substances (TBARS) was determined according to the method of Ohkawa et al. (1979). Glutathione was determined using the method of Beutler et al. (1963). Measurement of DNA fragmentation was based on the hydrolysis of DNA leading to release of free deoxyribose that was colorimetrically measured at $575 \mathrm{~nm}$ after reaction with the diphenylamine reagent according to Kurita-Ochiai et al. (1999). Superoxide anion was measured according the procedure of Prodczasy and Wei (1988), which is based on the reduction of iodonitrotetrazolium. Total peroxides was measured according to Harma and Erel (2005), based on the oxidation of zylenol orange into purple colored chromogen that is directly in proportion with the peroxide content in the presence of ferrous sulfate as catalyzer. Superoxide dismutase (SOD) activity was determined according to its ability to inhibit the autoxidation of epinephrine at alkaline medium according to Misra and Fridovich (1972). Catalase (CAT) activity was estimated by the procedure of Luck (1963), depending on its ability to decompose hydrogen peroxide $\left(\mathrm{H}_{2} \mathrm{O}_{2}\right)$. Glutathione S-transferase (GST) activity was assayed using 1-chloro-2,4dinirtobenzene as substrate according to the method of Superoxide dismutase (SOD) activity was determined according to its ability to 


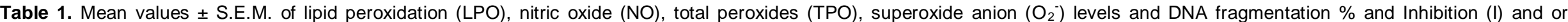
stimulation $(\mathrm{S}) \%$ in the lung and colon of control and different treated rats.

\begin{tabular}{|c|c|c|c|c|c|c|c|c|c|c|}
\hline \multirow{3}{*}{ Group } & \multicolumn{8}{|c|}{ Measurement (nmol /mg protein) } & & \\
\hline & \multicolumn{2}{|c|}{ LPO } & \multicolumn{2}{|c|}{ NO } & \multicolumn{2}{|c|}{ TPO } & \multicolumn{2}{|c|}{$0^{2}$} & \multicolumn{2}{|c|}{ DNA Fragmentation (\%) } \\
\hline & Lung & Colon & Lung & Colon & Lung & Colon & Lung & Colon & Lung & Colon \\
\hline $\mathrm{G} 1$ & $0.29 \pm 0.02$ & $0.19 \pm 0.01$ & $0.28 \pm 0.02$ & $0.90 \pm 0.18$ & $27.66 \pm 1.67$ & $14.41 \pm 1.28$ & $14.38 \pm 0.89$ & $20.69 \pm 1.22$ & $27.72 \pm 0.32$ & $24.19 \pm 0.77$ \\
\hline G2 & $0.77 \pm 0.04^{a^{* * *}}$ & $0.79 \pm 0.04^{a^{* * *}}$ & $0.57 \pm 0.04^{a^{* * *}}$ & $1.0 \pm 0.11$ & $79.92 \pm 3.95^{\mathrm{a}^{\star * *}}$ & $77.99 \pm 2.92^{\mathrm{a}^{\star \star \star *}}$ & $18.67 \pm 0.84^{a^{*}}$ & $24.81 \pm 1.56^{a^{*}}$ & $62.01 \pm 1.74^{a * * *}$ & $77.88 \pm 2.18^{a * * *}$ \\
\hline G3 & $0.81 \pm 0.04$ & $0.51 \pm 0.03^{b * * *}$ & $0.57 \pm 0.02$ & $1.05 \pm 0.19$ & $53.58 \pm 2.5^{\mathrm{b} * \star *}$ & $41.45 \pm 2.0^{b * * *}$ & $16.05 \pm 0.84$ & $19.68 \pm 0.99 \mathrm{~b} * *$ & $42.28 \pm 0.23^{b * * *}$ & $45.74 \pm 0.57^{b * * *}$ \\
\hline G4 & $0.88 \pm 0.04$ & $0.16 \pm 0.01^{\mathrm{b} * *}$ & $0.59 \pm 0.04$ & $0.65 \pm 0.06^{\mathbf{b}^{* * *}}$ & $34.35 \pm 1.34^{\mathrm{b} * * *}$ & $19.52 \pm 0.76^{\mathrm{b} * * *}$ & $19.73 \pm 1.50$ & $15.25 \pm 0.98^{\mathrm{b} * *}$ & $42.83 \pm 0.30^{b * * *}$ & $49.90 \pm 0.75^{b * * *}$ \\
\hline
\end{tabular}

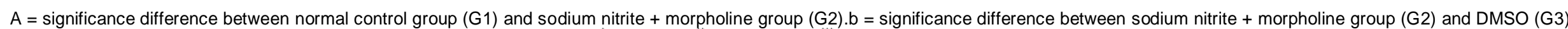
and 3-aminothiazolo[3-2a]benzimadzole-2-carbonitrile (G4) treated groups. $=P<0.05, \stackrel{=}{=}<0.01$ and $\stackrel{* * t}{=}=\mathrm{P}<0.001$.

inhibit the autoxidation of epinephrine at alkaline medium according to Misra and Fridovich (1972). Catalase (CAT) activity was estimated by the procedure of Luck (1963) depending on its ability to decompose hydrogen peroxide $\left(\mathrm{H}_{2} \mathrm{O}_{2}\right)$. Glutathione S-transferase (GST) activity was assayed using 1-chloro-2,4-dinirtobenzene as substrate according to the method of Habig et al. (1974). Vit E was measured using Emmerie-Engel reaction based on the reduction of ferric to ferrous ions, forming a red complex with a,a-dipyridyl according to the method of Roe (1961). Ceruloplasmin (CP) content was determined colorimetrically with $0.1 \%$ para-phenylenediamine reagent according the method of Houchin (1958).

\section{Histological studies}

Pieces of lung and colon were quickly removed and fixed in $10 \%$ neutral buffered formalin for histological and immunohistochemical investigations. Then sections $(7 \mu \mathrm{M})$ were mounted on slides and dried overnight at $37^{\circ} \mathrm{C}$. The sections were dewaxed in xylene and hydrated in a graded series of alcohols and stained with Harris hematoxylin and eosin according to Drury and Wallington (1980).

\section{Immunoperoxidase studies}

Immunohistochemical staining for iNOS was performed using a standardized streptavidin-biotin-peroxidase method on formalin-fixed paraffin-embedded tissues according to
Zhou et al. (2002). After deparaffinization, sections were treated with $5 \%$ hydrogen peroxidase for 5 min to block endogenous peroxidase activity. Incubation with 1.5\% normal horse serum for 35 min prevents nonspecific antigen binding. Sections were incubated with primary antibodies (BD Biosciences, San Diego, CA, USA) overnight at $4^{\circ} \mathrm{C}$, followed by incubation for $45 \mathrm{~min}$ with the biotinylated secondary antibody, and subsequently incubated for $50 \mathrm{~min}$ in avidin-biotinylated peroxidase complex reagent (Vectastain Rabbit ABC Elite Kit; Vector Laboratories, Burlingame, CA, USA). Signals were developed by treatment with diaminobenzidine tetrahydrochloride (Sigma, St. Louis, MO, USA) for $5 \mathrm{~min}$ The slides were counterstained with Mayer's hematoxylin dehydrated and mounted with D.P.X (BDH Ltd, Poole, UK) For negative controls, the primary antibody recognizing iNOS was omitted or replaced by the isotype-matched mouse lgG2a (BD Biosciences, UK) according to Zhang et al. (2008). The positive controls consisted of rat lung tissue.

\section{Statistical analysis}

The results were analyzed by one way analysis of variance (ANOVA) followed by Newman-Keuls multiple comparison test as post-test by using Prism program for windows, version 3.0 (Graph pad software, Inc., San Diago CA USA). The significant difference between groups was accepted at $\mathrm{P}<0.05$.

\section{RESULTS}

The results of oxidative stress biomarkers in lung and colon tissues of control and different treated rats were presented in Tables 1 to 3 . As shown in Table 1, administration of sodium nitrite plus morpholine significantly increased lipid peroxidation (LPO), NO, total peroxides (TPO) and superoxide anion $\left(\mathrm{O}_{2}^{-}\right)$levels and DNA fragmentation percent of the lung and colon versus those of control rats. When 3aminothiazolo[3-2a]benzimadzole-2-carbonitrile or its solvent DMSO was given to sodium nitrite and morpholine administered rats, they significantly inhibited the increase of LPO, NO, TPO and $\mathrm{O}_{2}{ }^{-}$in colon and DNA fragmentation percent in lung and colon.

The activity of SOD was inhibited; however glucose-6-phosphate dehydrogenase (G6PD) was enhanced in the lung and colon of rats treated with nitrite and morpholine compared to the control. Moreover, CAT and GST activities were increased in the lung and decreased in the colon of rats treated with nitrite and morpholine versus those of controls. The administration of 3aminothiazolo[3-2a]benzimadzole-2-carbonitrile or 
Table 2. Mean Values \pm S.E.M of superoxide dismutase (SOD), catalase (CAT), glutathione S- transferase (GST) and glucose 6 phosphate dehydrogenase (G6PD) activities and inhibition (I) and or stimulation (S) \% in lung and colon of control and different treated rats.

\begin{tabular}{|c|c|c|c|c|c|c|c|c|}
\hline \multirow{2}{*}{ Group } & \multicolumn{2}{|c|}{ SOD (U/min/mg protein) } & \multicolumn{2}{|c|}{ CAT (U/min/mg protein) } & \multicolumn{2}{|c|}{ GST (nmol/min/mg protein) } & \multicolumn{2}{|c|}{ G6PD (nmol/min/mg protein) } \\
\hline & Lung & Colon & Lung & Colon & Lung & Colon & Lung & Colon \\
\hline G1 & $1.29 \pm 0.07$ & $2.77 \pm 0.17$ & $3.09 \pm 0.21$ & $3.13 \pm 0.14$ & $19.36 \pm 0.88$ & $35.37 \pm 1.44$ & $1.01 \pm 0.07$ & $1.07 \pm 0.08$ \\
\hline G2 & $0.92 \pm 0.12^{a_{*}}$ & $0.82 \pm 0.02^{a_{\star \star \star}}$ & $11.5 \pm 1.19^{a_{\star \star \star}}$ & $2.25 \pm 0.19$ & $33.32 \pm 1.3^{a_{\star \star \star}}$ & $20.39 \pm 2.17^{a \star \star \star}$ & $1.33 \pm 0.080^{a_{\star \star}}$ & $1.45 \pm 0.09^{a_{\star \star}}$ \\
\hline G3 & $1.45 \pm 0.20^{\mathrm{b} * *}$ & $3.17 \pm 0.18^{\mathrm{b} * * *}$ & $7.2 \pm 0.21^{b *}$ & $2.91 \pm 0.24$ & $59.52 \pm 2.87^{b_{* * *}}$ & $26.38 \pm 1.09^{b *}$ & $1.45 \pm 0.13$ & $1.34 \pm 0.04$ \\
\hline G4 & $0.54 \pm 0.05^{\mathrm{b} * *}$ & $1.15 \pm 0.097^{b * * *}$ & $16.4 \pm 1.43^{\mathrm{b} * *}$ & $6.20 \pm 0.63^{b_{* * *}}$ & $28.41 \pm 2.09$ & $40.76 \pm 1.59^{b * * *}$ & $1.25 \pm 0.10$ & $1.63 \pm 0.04$ \\
\hline
\end{tabular}

$\mathrm{a}=$ significance difference between normal control group (G1) and sodium nitrite + morpholine group (G2).b = significance difference between sodium nitrite + morpholine group (G2) and DMSO (G3) and 3-aminothiazolo[3-2a]benzimadzole-2-carbonitrile (G4) treated groups. $=P<0.05, \stackrel{*}{*}=P<0.01$ and ${ }^{* * *}=P<0.001$.

Table 3. Mean values \pm S.E.M. of vitamin $E$ (Vit E), vitamin $C$ (Vit C), glutathione (GSH) and ceruloplasmin (CP) in lung and colon of control and different treated rats.

\begin{tabular}{|c|c|c|c|c|c|c|c|c|}
\hline \multirow{2}{*}{ Groups } & \multicolumn{2}{|c|}{ Vit E ( $\mu / \mathrm{mg}$ protein) } & \multicolumn{2}{|c|}{ Vit $\mathbf{C}(\mu / \mathrm{mg}$ protein) } & \multicolumn{2}{|c|}{ GSH ( $\mu / \mathrm{mg}$ protein) } & \multicolumn{2}{|c|}{ CP ( $\mu / \mathrm{mg}$ protein) } \\
\hline & Lung & Colon & Lung & Colon & Lung & Colon & Lung & Colon \\
\hline G1 & $10.84 \pm 0.35$ & $8.87 \pm 0.65$ & $3.79 \pm 0.27$ & $4.83 \pm 0.12$ & $1.35 \pm 0.040$ & $1.54 \pm 0.055$ & $19.25 \pm 0.74$ & $8.82 \pm 0.43$ \\
\hline G2 & $8.75 \pm 0.60^{a_{*}}$ & $13.11 \pm 0.38^{a_{* \star *}}$ & $3.84 \pm 0.15$ & $8.25 \pm 0.27^{a * \star *}$ & $1.80 \pm 0.060^{a * \star \star}$ & $2.34 \pm 0.065^{\mathrm{a}^{\star \star \star \star}}$ & $8.94 \pm 0.57^{a \star \star \star}$ & $0.58 \pm 0.04^{a * \star \star}$ \\
\hline G3 & $10.30 \pm 0.47^{b_{*}}$ & $11.16 \pm 0.42^{b_{* *}}$ & $2.81 \pm 0.14^{b_{* *}}$ & $3.79 \pm 0.27^{b_{* \star *}}$ & $1.24 \pm 0.05^{b_{* \star *}}$ & $1.29 \pm 0.03^{b_{* \star \star}}$ & $5.63 \pm 0.36^{b_{* \star \star}}$ & $1.06 \pm 0.12$ \\
\hline G4 & $5.20 \pm 0.31^{b_{* \star *}}$ & $8.58 \pm 0.39^{b_{* \star *}}$ & $2.97 \pm 0.13^{b_{* *}}$ & $4.87 \pm 0.24^{b_{* \star *}}$ & $1.33 \pm 0.05^{\mathrm{b} * * *}$ & $1.41 \pm 0.03^{b_{* \star \star}}$ & $6.32 \pm 0.36^{b_{* \star *}}$ & $2.03 \pm 0.15^{\mathrm{b} * * *}$ \\
\hline
\end{tabular}

$\mathrm{a}=$ Significance difference between normal control group (G1) and sodium nitrite + morpholine group (G2). $\mathrm{b}=$ Significance difference between sodium nitrite + morpholine group (G2) and DMSO (G3) and 3-aminothiazolo[3-2a]benzimadzole-2-carbonitrile (G4) treated groups. ${ }^{*}=P<0.05, \stackrel{* *}{=} P<0.01$ and ${ }^{* * *}=P<0.001$.

its solvent DMSO stimulated the SOD, CAT and GST activities, but it did not significantly change the G6PD activity in the lung and colon tissues (Table 2). Nitrite and morpholine administration to the rats also increased the vit $\mathrm{E}$, vit $\mathrm{C}$ and $\mathrm{GSH}$ concentration, but decreased CP levels in the lung and colon tissues compared to those of controls. In addition, treatment of rats with 3aminothiazolo[3-2a]benzimadzole-2-carbonitrile or its solvent DMSO restored the changes that were caused by nitrite plus morpholine treatment (table 3). Histological examination of the lung sections of control rats after staining with $\mathrm{H} \& \mathrm{E}$ showed normal appearance of the bronchiole lined by pseudo stratified columnar epithelium with healthy interstitial tissue (Figure 1a). Treatment of rats with nitrite plus morpholine showed large sized aggregated lymph follicle in a close relation to bronchioles (Figure 1b). Co-treatment of rats with DMSO revealed that aggregated groups of mononuclear cell are still found between bronchioles (Figure 1c). Concerning the co-treatment of rats with 3-aminothiazolo[3-2a]benzimadzole-2 carbonitrile, the histological examination showed more or less normal appearance of the bronchioles with almost normal interstitial tissue (Figure 1d). Histological observation of the colon sections of control rats (Figure 1e) showed longitudinal section in the crypts that are lined by columnar cells with oval basal nuclei and separated by goblet cells Scattered mononuclear cells are also observed in the interstitial tissue. Treatment of rats with nitrite plus morpholine for 15 weeks showed disturbed mucosal architecture and pronounced infiltration of mononuclear cells (Figure 1f). Rats co-treated with DMSO showed localized large aggregation of mononuclear cells infiltration in lamina propria (Figure 1g), while colon of rats co-treated with 3-aminothiazolo[32a]benzimadzole-2-carbonitrile showed few scattered mononuclear cells in lamina propria with more or less normal appearance of the crypts (Figure 1h). Immuno-staining lung for iNOS showed negative reaction either in the bronchiole or in the interstitial tissue (Figure2a), After treatment 


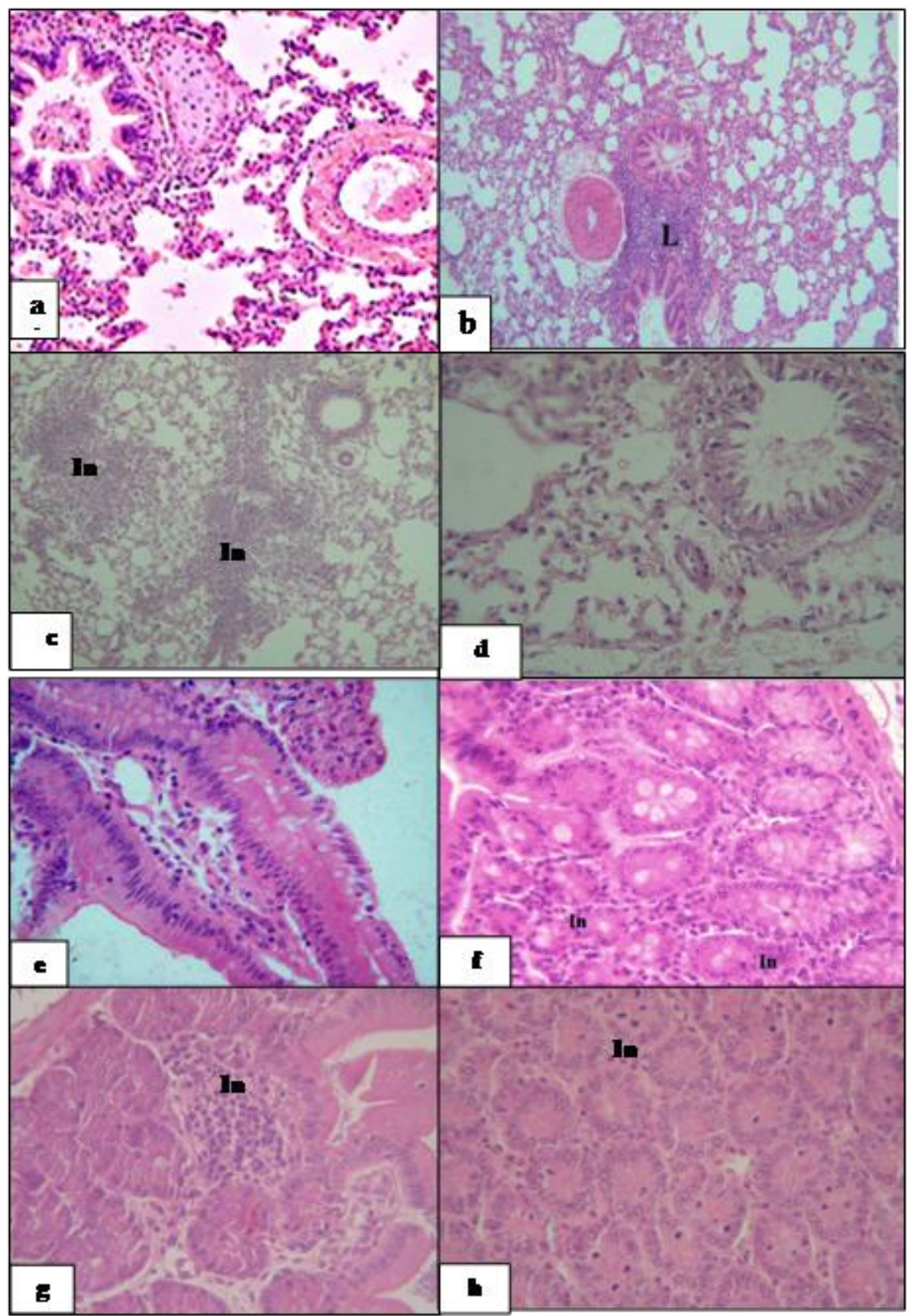

Figure 1. A photomicrograph for $H \& E$ staining in lung and colon $X 400$ showing: (a) normal appearance of the bronchiole lined by pseudostratified columnar epithelium with healthy interstitial tissue; (b) large sized aggregated lymph follicle (L) in a close relation to bronchioles in rat treated by nitrite and morpholine; (c) aggregated groups of mononuclear cell infiltration (In) found between bronchioles in rat co-treated with DMSO; (d) more or less normal appearance of the bronchioles with almost normal interstitial tissue in lung of 3-aminothiazolo[3-2a]benzimadzole-2-carbonitrile co-treated rat; (e) longitudinal section in the crypts that are lined by columnar cells with oval basal nuclei and separated by goblet cells, few scattered mononuclear cells are observed in the interstitial tissue of normal colon; (f) disturbed mucosal architecture and pronounced infiltration of inflammatory cells $(\mathrm{In})$ in colon of rats treated with nitrite and morpholine; $(\mathrm{g})$ localized large aggregation of mononuclear cells infiltration (In) in lamina propria in colon of rats co-treated with DMSO; (h) few scattered mononuclear cells in lamina propria with more or less normal appearance of the crypts in colon of rats co-treated with 3aminothiazolo[3-2a]benzimadzole-2-carbonitrile. 

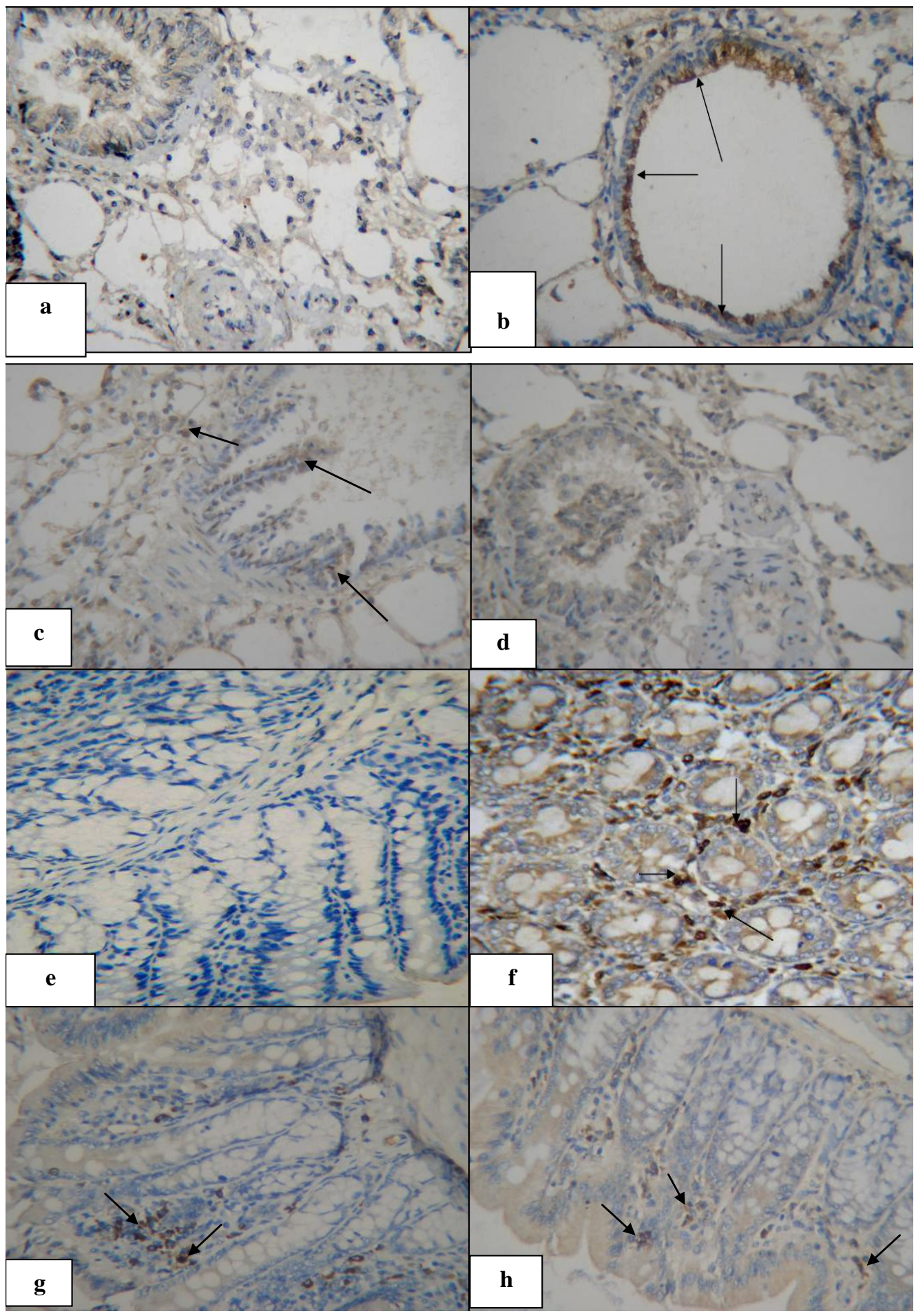

Figure 2. A photomicrograph for iNOS staining in lung and colon X400 showing (a) nearly negative reaction either in the bronchiole or in the interstitial tissue; (b) positive reaction in the lining cells of the small bronchiole (arrows) in lung of nitrite and morpholine treated rats; (c) scattered positive cells in the bronchiole and in the interstitial tissue (arrows) in rat co-treated with DMSO; (d) nearly negative reaction either in the bronchiole or in the interstitial tissue in lung of 3-aminothiazolo[32a]benzimadzole-2-carbonitrile co-treated rat; (e) no reaction was observed in normal colon; (f) positive reaction localized primarily in the mononuclear cells of the lamina propria (arrows) in colon of rats treated with nitrite and morpholine; $(\mathrm{g})$ scattered positive mononuclear cells in lamina propria (arrow) in colon of rats co-treated with DMSO; $(\mathrm{h})$ areas with less intense reaction localized in the apical cytoplasm (arrows) in colon of rats co-treated with 3-aminothiazolo[3-2a]benzimadzole-2carbonitrile. 
treatment with nitrite plus morpholine for 15 weeks, positive reaction in the lining cells of the small bronchiole was detected (Figure 2b). Lung of rats co-treated with DMSO showed scattered positive cells in the bronchiole and in the interstitial tissue (arrows) (Figure 2c). However, lung of rats co-treated with 3-aminothiazolo[32a]benzimadzole-2-carbonitrile showed nearly negative reaction either in the bronchiole or in the interstitial tissue (Figure 2d). Immuno-staining colon for iNOS revealed negative reaction (Figure $2 \mathrm{e}$ ), after treatment with nitrite plus morpholine for 15 weeks, colon showed intense positive reaction in mononuclear cells of the lamina propria (Figure 2f). Furthermore, the colon of rats cotreated with DMSO showed scattered positive mononuclear cells in lamina propria (arrow) (Figure 2g), however, colon of rats co-treated with 3-aminothiazolo[32a]benzimadzole-2-carbonitrile showed areas with less intense reaction; this is primarily localized in the apical cytoplasm (arrows) (Figure 2h).

\section{DISCUSSION}

Many human cancers may be caused by the environmental factors such as traces of nitrosamines, so it was important to check up the effects of those chemicals at relatively low doses (Futakuchi et al., 1999). It is well known that in the presence of nitrite, MOR can be converted to NMOR both in vitro and in vivo. NMOR is widely used as hepatocarcinogen in experimental models and might induce DNA damage via formation of ROS/RNS (Robichová et al., 2004; Erkekoglu and Baydar, 2010). In the current study, TPO, LPO, NO and $\mathrm{O}_{2}^{-}$were significantly increased in the lung and colon tissues of rats treated with nitrite combined with MOR for 15 weeks. In this aspect, elevation of ROS may be one of the contributing factors in the mechanisms of nitrate tolerance (Watanabe et al., 1998). Moreover, nitrosamines are metabolized by cytochrome P-450 dependent monoxidases system, generating a variety of ROS which are responsible for the onset of the toxic effects of nitrosamines (Mostafa and Shewita, 1992). Induction of carcinogen-metabolizing enzymes plays a critical step in initiation of carcinogenesis caused by nitrosamines (Sheweita, 2000). Increased concentration of ROS is involved in pathological processes leading to the development of cancer and other diseases (Cerutti, 1994). Nitrite production by inflammatory cells, in combination with amine production by bacteria, results in formation of carcinogenic nitrosamines (Roediger et al., 1990).

The possible production of ROS is reflected in an increase in LPO, which is an important process in cellular damage. Consequently, in the present study, DNA fragmentation and LPO were significantly elevated in the lung and colon tissues of rats treated with nitrite plus MOR. The present data confirmed that ROS such as $\mathrm{O}_{2}{ }^{-}$,
$\mathrm{OH}^{-}$and $\mathrm{H}_{2} \mathrm{O}_{2}$ produced in the metabolism of NMOR was formed endogenously from the administration of nitrite plus MOR (Bansal et al., 2005). In this aspect, NMOR is widely used as a carcinogen in experimental animal models and its DNA-damaging activity was confirmed by Korr et al. (2001) and Robichová and Slame`nová (2001). NMOR induce DNA damage via at least two different pathways: directly via formation of $\mathrm{NO}$ and indirectly through $\mathrm{N}$-hydroxylamines generated by drugmetabolizing enzymes (Robichová et al., 2004). Moreover, ROS/RNS are potent intrinsic stimuli for apoptosis that modulate apoptosis when cell are under stress by mitochondrial damage (Reed, 1997). Also, increased ROS/RNS levels are extensively involved in the mechanisms of chronic lung inflammation contributing to the development of lung cancer (Azad et al., 2008).

Synthetic antioxidant compounds are required from external sources for direct interference in the carcinogenic process or scavenging and quenching carcinogens or preventing their synthesis (Frenech and Ferguson, 2001). In the present study, co-treatment of rats with either 3aminothiazolo[3-2a]benzimadzole-2-carbonitrile or DMSO resulted in reduction of the TPO and LPO levels and DNA fragmentation $\%$ in the lung and colon tissues. In consistence, 5-nitro-2-(phenoxymethyl) benzimidazole significantly inhibited LPO, which was similar to that observed with butylated hydroxytoluene (BHT), a wellknown antioxidant. This action was returned to the $\mathrm{O}_{2}$ scavenging activity of the synthesized compounds at different concentration (Olorunisola et al., 2011). In addition, synthesized benzimidazole depending on the tissue have variable effects on cytochrome $P_{450}$ system which is also known to be expressed and regulated differentially in various tissues by numerous xenobiotics (Iscan et al., 1989). DMSO, a known to be an effective hydroxyl radical scavenger (Del Maestro et al., 1980), may act to neutralize the cytotoxic effects of hydroxyl radicals in mitochondria themselves (Schlafer et al., 1982) and can lower oxygen utilization during cellular ischemia (Ghosh et al., 1976).

Dietary nitrate increased gastric NO levels and potently protected against the macroscopic injury caused by nonsteroidal anti-inflammatory drugs (NSAID) exposure (Lundberg et al., 2008). Additionally, nitrate pretreatment decreased mucosal myeloperoxidase activity and the expression of iNOS, which is indicative of reduced tissue inflammation. The protection afforded by nitrate probably is related to increase gastric mucosal blood flow (Peterson et al., 2007). GSH-GSSG antioxidant system protects macrophages from large amounts of NO produced by iNOS as in the present study (Coleman, 2001). Oxygen free radical enzymatic scavengers like SOD, CAT, glutathione peroxidase (GPx), GST, glutathione reductase (GR), and G6PDH may protect the system from deleterious effect (Banerjee et al., 1999). In the present study, the alterations in the activities of SOD, CAT, GST and G6PD in lung and colon tissues of all the 

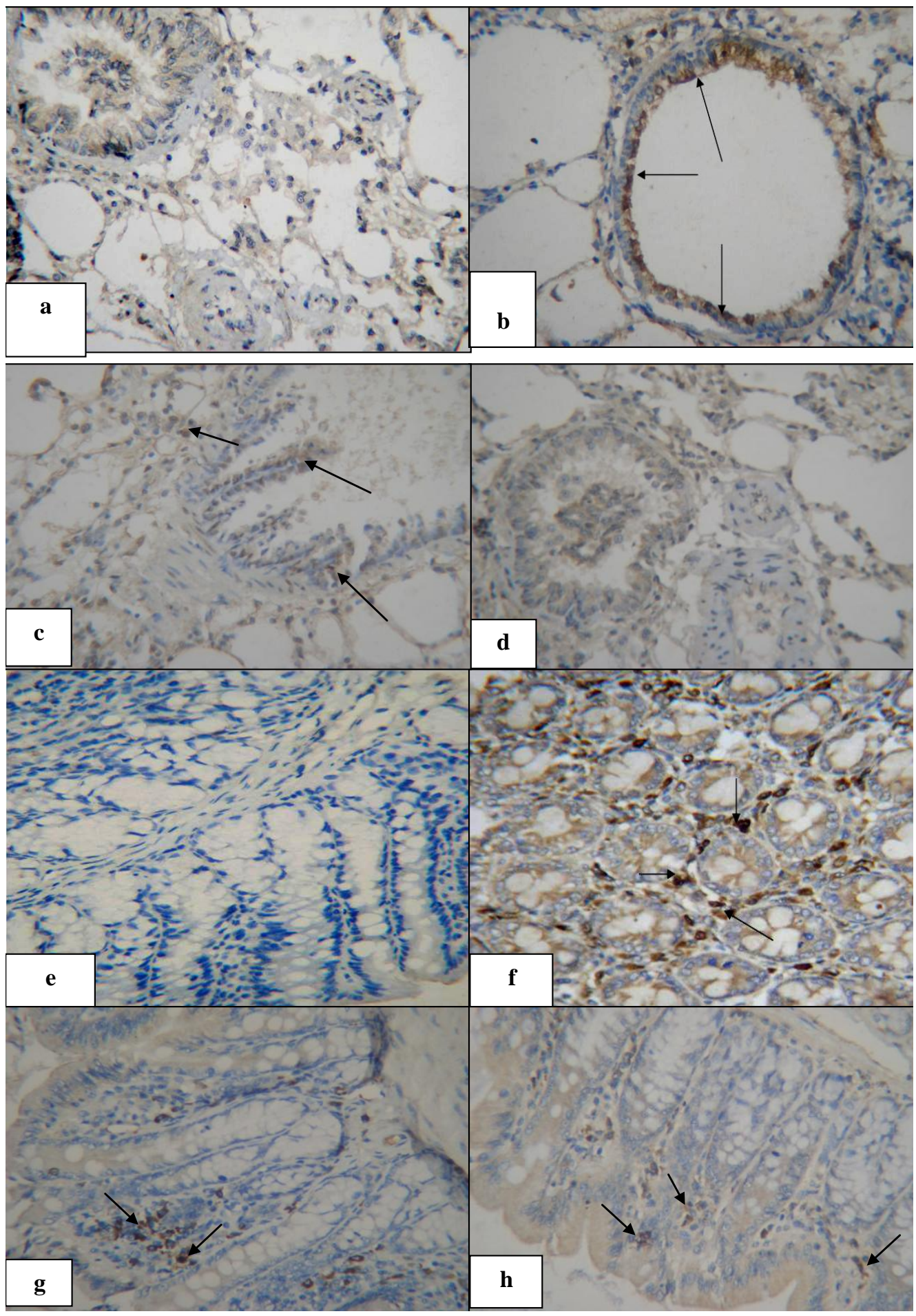

Figure 2. A photomicrograph for iNOS staining in lung and colon X400 showing (a) nearly negative reaction either in the bronchiole or in the interstitial tissue; (b) positive reaction in the lining cells of the small bronchiole (arrows) in lung of nitrite and morpholine treated rats; (c) scattered positive cells in the bronchiole and in the interstitial tissue (arrows) in rat co-treated with DMSO; (d) nearly negative reaction either in the bronchiole or in the interstitial tissue in lung of 3-aminothiazolo[32a]benzimadzole-2-carbonitrile co-treated rat; (e) no reaction was observed in normal colon; (f) positive reaction localized primarily in the mononuclear cells of the lamina propria (arrows) in colon of rats treated with nitrite and morpholine; $(\mathrm{g})$ scattered positive mononuclear cells in lamina propria (arrow) in colon of rats co-treated with DMSO; $(\mathrm{h})$ areas with less intense reaction localized in the apical cytoplasm (arrows) in colon of rats co-treated with 3-aminothiazolo[3-2a]benzimadzole-2carbonitrile. 
treated rats might result from increased ROS production. In consistence, increased oxidative stress due to increased production of ROS may alter the antioxidant system (Dröge, 2002). SOD is responsible for the dismutation of $\mathrm{O}_{2}^{-}$to $\mathrm{H}_{2} \mathrm{O}_{2}$, which is neutralized by the combined action of CAT and GPx (Mates, 2000). The decreased level of SOD activity, suggests an increased $\mathrm{O}_{2}$ production. In the present study, reduced CAT activity in colon tissue of nitrite and morpholine-treated rats may be due to the fact that colon cells have reduced amount of peroxisomes. GST provides protection to the tissues by catalyzing the conjugation of a variety of electrophilic xenobiotics to GSH (Chasseaud, 1979). G6PDH enzymes play an important role in maintaining GSH redox state. The stimulated activity of G6PDH in the present study may be accrued to the increased supply of NADPH for catalytic activity of GR (Markey, 1998). GSH quenches toxic hydroperoxides catalyzed by GPx and conjugation reactions catalyzed by GST (Chasseaud, 1979). In the present study, decreased level of GSH by GMSO and 3-aminothiazolo[3-2a]benzimadzole-2carbonitrile could seriously impair the optimal functioning catalytic activities of various GSH dependent enzymes (Mates, 2000).

Vitamin $E$ is the most effective chain-breaking, lipidsoluble antioxidant weapon that inhibits LPO induced by ROS. The altered level of Vit $E$ in the present study indicates the subnormal scavenging of LPO. Vit C scavenges many different types of free radicals and is also capable of regenerating Vit E from the tocopheroxy radicals that are generated during the a-tocopherol mediated inhibition of LPO (Dieber-Rotheneder et al., 1991). The reduction of Vit $C$ in lung and colon tissues of GMSO and 3-aminothiazolo[3-2a]benzimadzole-2carbonitrile treated rats may be due to the decrease in the recycling of Vit $C$ (Rumpsey and Levine, 1998). The capability of DMSO as antioxidant to scavenge free radicals that gather at the site of injury has been observed in experiments with laboratory animals and in ulcerative colitis patients (Itoh and Guth, 1985; Salim, 1992). Moreover, DMSO was found to prolong the survival rates in rats and protect non cancer cells while potentiating the chemotherapeutic drug (Salim, 1992). Also, promising group of antitumor compounds is represented by benzimidazole [1,2-c] quinazolines and thiazolo [3,4-a] benzimidazole (Spasov et al., 1999).

In the present study, ceruloplasmin levels were significantly increased in lung and colon of rats treated with nitrite and morpholine. Inoue et al. (1999) reported that ceruloplasmin favors the formation of Snitrosoglutathione when added to cultured monocytes expressing iNOS. Whereas, nitrothiol adducts of NO function as NO transporters and are involved in modulation of intracellular and intercellular signal transduction (Akailke, 2000). Moreover, different mechanism highlight the enhancement of LPO by catalytic amounts of ceruloplasmin in the presence of iron plus GSH-derived thiols or ascorbate, a system which is also able to promote mutagenesis (Glass and Stark, 1997). In contrast, Beieli and Calabrese (2002) claimed that ceruloplasmin could benefit the organism under some pathophysiological conditions, such as neovascularization of injured tissues.

\section{Conclusions}

Nitrite plus morpholine administration to rats results in oxidative injury in pulmonary and colon tissues as evidenced by biochemical changes and morphological changes. This injury may cause the increased production of ROS/RNS and changes in the levels of antioxidants which were ameliorated by 3-aminothiazolo[32a]benzimadzole-2-carbonitrile and DMSO.

\section{REFERENCES}

Akailke T (2000). Mechanisms of biological S-nitrosation and its measurement. Free Radic. Res. 33:61-469.

Azad N, Rojanasakul Y, Vallyathan V (2008). Inflammation and lung cancer: Role of reactive oxygen/nitrogen species. J. Toxicol. and Env. Health, Part B, 11:1-15.

Banerjee BD, Seth V, Bhattacharya A, Paisha ST, Chakraborty AK (1999). Biochemical effects of some pesticides on lipid peroxidation and free radical scavengers. Toxicol Lett, 107:33-47.

Bansal AK, Bansal M, Soni G, Bhatnagar D (2005). Protective role of vitamin $\mathrm{E}$ pre-treatment on $\mathrm{N}$-nitrosodiethylamine induced oxidative stress in rat liver. Chemico-Biological Interactions, 1562:101-111.

Bartsch H, Hietanen E, Malaveille C (1989). Carcinogenic nitrosamines: free radical aspects of their action. Free Radic Med Biol. 7: 637-644.

Beutler E, Duron O, Kelly BM (1963). Improved method for the determination of blood glutathione. J. Lab. Clin. Meth. 61:882-888.

Bielli P, Calabrese L (2002). Structure to function relationship in ceruloplasmin: a 'moonlighting protein'. Cell. Mol. Life Sci. 59:1413-1427.

Cerutti P, Ghosh R, Oya Y, Amstad P (1994). The role of the cellular antioxidant defense in oxidant carcinogenesis. Environ. Health Perspect. 10: 123-129.

Chasseaud LF (1979). The role of glutathione and glutathione-Stransferases in the metabolism of chemical carcinogens and other electrophilic agents. Adv Cancer Res. 29:175-274.

Coleman JW (2001). Nitric oxide in immunity and inflammation. Int. Immunopharmacol. 1:1397-1272.

Del Maestro R, Thaw HH, Bjork J, Planker M, Arfors KE (1980). Free radicals as mediators of tissue injury. Acta. Physiol. Scand. Suppl. 492:91-119.

Dieber-Rotheneder M, Puhl H, Waeg G, Striegl G, Esterbauer H (1991). Effect of oral supplementation with d-a-tocopherol on the vitamin $E$ content of human low density lipoproteins and resistance to oxidation. J. Lipid Res. 32:1325-1332.

Drury RAB, Wallington EA (1980). Carlton's histological technique. 5 ed Oxford, New York, Toronto. Oxford Univ. Press, Oxford; 232-259.

Dröge W (2002). Free radicals in the physiological control of cell function. Physiol. Rev. 82 (1):47-95.

Erkekoglu P, Baydar T (2010). Evaluation of the protective effect of ascorbic acid on nitrite- and nitrosamine-induced cytotoxicity and genotoxicity in human hepatoma line. Toxicol. Mech. Methods, 20(2):45-52.

Frenech M, Ferguson LR (2001). Vitamins/minerals and genomic stability in humans. Mutat. Res. 475:1-6.

Futakuchi M, Hirose M, Ogiso T, Kato K, Sano M, Ogawa K, Shirai T (1999). Establishment of an in vivo highly metastatic rat hepatocellular carcinoma model. Jpn J. Cancer Res. 90(11):01196-202.

Geiss J (2001). The century of space science. Kluwer Academic. p. 20. http://books.google.com/books?id=22FJysl_WcC\&pg=PA20\#v=one page\&q\&f=false. Retrieved 2011 Aug 7. 
Ghosh AK, Ito T, Ghosh S, Sloviter HA (1976). Effects of dimethyl sulfoxide on metabolism of isolated perfused rat brain. Biochem Pharmacol. 25:1115-1117.

Glass GA, Stark AA (1997). Promotion of glutathione- gamma-glutamyl transpeptidase-dependent lipid peroxidation by copper and ceruloplasmin the requirement for iron and the effects of antioxidants and antioxidant enzymes. Environ. Mol. Mutagen. 29:73-80.

Habig WH, Pabst MJ, Jokoby WB (1974). Glutathion S-Transferase. J. Biol. Chem. 249:7130- 7139.

Harma M, Erel O (2005). Measurement of the total antioxidant response in preeclampsia with a novel automated method. Eur. J. Obstet. Gynecol. Reprod. Biol. 118:47-51.

Hjorth SA, Adelhorst K, Pedersen BB, Kirk O, Schwartz TW (1994). Glucagon and glucagon-like peptide-1: selective receptor receognition via distinct peptide epitopes. J. Biol. Chem. 269: 30:121 124.

Houchin OB (1958). A rapid colorimetric method for the quantitative determination of copper oxidase activity (Ceruloplasmin). Clinic. Chem. 4:519-523.

Hord NG, Tang Y, Bryan N (2009). Food sources of nitrates and nitrites: the physiologic context for potential health benefits. Am. J. Clin Nutr. 90:1-10.

Iscan MY, Buyukbingol E, Iscan M, Sahin F, Safak C (1989). Effects of 2-arylbenzimidazoles on rat hepatic microsomal monooxygenase system. Comp. Biochem. Physiol. 92C:109-115.

Inoue K, Akailke T, Miyamoto Y, Okamoto T, Sawa T, Otagiri M (1999). Nitrosothiol formation catalyzed by ceruloplasmin: implication for cytoprotective mechanism in vivo. J. Biol. Chem., 274: 27069-27075.

Itoh M, Guth P (1985). Role of oxygen-derived free radicals in hemorrhagic shock-induced gastric lesions in the rat. Gastroenterol. 88:1126-1167.

Korr H, Botzem B, Schmitz C, Enzmann H (2001). N-Nitrosomorpholine induced alterations of unscheduled DNA synthesis, mitochondrial DNA synthesis and cell proliferation in different cell types of liver, kidney, and urogenital organs in the rat. Chem. Biol. Interact. 134:217-233.

Kitano M, Takada $\mathrm{N}$, Chen $\mathrm{T}$, Ito $\mathrm{H}$, Nomura $\mathrm{T}$, Tsuda $\mathrm{H}$, Wild $\mathrm{CP}$, Fukushima $S$ (1997). Carcinogenicity of methylurea or morpholine in combination with sodium nitrite in rat multi-organ carcinogenesis bioassay. Jpn. J. Cancer Res. 88: 797-806.

Kurita-Ochiai T, Fukushima K, Ochiai K (1999). Lipopolysaccharide stimulates butyric acid-induced apoptosis in human blood mononuclear cells. Infect. Immun. 67(1):22-29.

Lowry OH, Rosebrough NJ, Farr AL, Randall RJ (1951). Protein measurement with the Folin phenol reagent. J. Biol. Chem. 41:18631870.

Luck H (1963). Catalase. In: Bergmer HU (ed.), Methods of enzymatic analysis. Academic Press, New York. pp. 885-888.

Lundberg JO, Weitzberg E, Gladwin M (2008). The nitrate-nitrite-nitric oxide pathway in physiology and therapeutics. Nat. Rev. Drug Discov. 7:156-167.

Mates JM (2000). Effects of antioxidant enzymes in the molecular control of reactive oxygen species toxicology. Toxicology 153:83-104.

Markey CM, Rudolph DB, Labus JC, Hinton BT (1998). Oxidative stress differentially regulates the expression of $y$-glutamyl transpeptidase mRNAs in the initial segment of the rat epididymis. J. Androl. 19:9299.

Michel T, Feron O (1997). Nitric oxide synthases-which, where, how, and why. J. Clin. Investig. 100:2146-2152.

Mirvish SS (1995). Role of $\mathrm{N}$-nitroso compounds (NOC) and $\mathrm{N}$ nitrosation in etiology of gastric, esophageal, nasopharyngeal and bladder cancer and contribution to cancer of known exposures to NOC. Cancer Lett. 93:17-48.

Mirvish SS, Pelfrene AF, Garcia H, Shubik P (1976). Effect of sodium ascorbate on tumor induction in rats treated with morpholine and sodium nitrite, and with nitrosomorpholine. Cancer Lett. 2(2):101-108.

Misra HP, Fridovich I (1972). The role of superoxide anion in the autoxidation of epinephrine and a simple assay for superoxide dismutase. J. Biol. Chem. 247:3170-3175.

Mostafa MH, Shewita SA (1992). Modification of the oxidative Ndemethylation of dimethylnitrosamine by various anti-inflammatory drugs. Ramazzini Newslett. 2:15-22.
Mumtaz MM, Sipes IG, Clewell HJ, Yang RSH (1993). Risk sessment of chemical mixtures: biologic and toxicologic issues (symposium overview). Fund. Appl. Toxicol. 21:258-269.

Ohkawa H, Ohishi N, Yagi K (1979). Assay for lipid peroxides in animal tissue by thiobarbaturic acid reaction. Anal. Biochem. 95:351-358.

Olorunisola OS, Akintola AO, Afolayan1 AJ (2011). Hepatoprotective and antioxidant effect of Sphenocentrum jollyanum (Menispermaceae) stem bark extract against $\mathrm{CCl} 4$ - induced oxidative stress in rats. Afr. J. Pharm. Pharmacol. 5(9):1241-1246.

Peterson J, Phillipson M, Jansson EA, Patzak A, Lundberg JO, Holm L (2007). Dietary nitrate increases gastric mucosal blood flow and mucosal defense. Am. J. Physiol. Gastointest. Liver Physiol. 292:G718-G724.

Prodczasy JJ, Wei R (1988). Reduction of iodonitrotetrazolium violet by superoxide radicals. Biochem. Biophys. Res. Commun. 150:12941301.

Reed JC (1997). Cytochrome C: can't live with live with it-can't live without it. Cell 91: 559-562.

Roe JH (1961). Standard methods of clinical chemistry. Vol III, Seligson. D (ed). Academic Press, New York. P 35.

Robichová S, Slame`Nová D, Chalupa I, Ebová L (2004). DNA lesions and cytogenetic changes induced by $\mathrm{N}$-nitrosomorpholine in HepG2, V79 and VH10 cells: the protective effects of vitamins A, C and E. Mutagenesis 560(13):91-99.

Roediger WEW, Lawson MJ, Radcliffe BC (1990). Nitrite from inflammatory cells-a cancer risk factor in ulcerative colitis? Dis. Colon Rectum 33:1034-1036.

Robichová S, Slame nová D (2001). Study of $N$ - nitrosomorpholin einduced DNA strand breaks in Caco-2 cells by the classical and modified comet assay: influence of vitamins $E$ and $C$. Nutrition 39:267-272.

Rumpsey SC, Levine M (1998). Absorption, transport and disposition of ascorbic acid in humans. Nutr. Biochem. 9:116-130.

Salim AS (1992). Role of oxygen-derived free radical scavengers in the management of recurrent attacks of ulcerative colitis: A new approach. J. Lab. Clin. Med. 119:740-747.

Sarhan AAO, EISherif HAH, Mahmoud AM, Habib OMA (2008). Synthesis, characterization and studies of new 3-benzyl-4H-1,2,4triazole-5-thiol and thiazolo[3,2-b][1,2,4]triazole-5(6H)-one heterocycles. Heterocyclic Chem. 45:897-908.

Schlafer M, Kane RF, Kirsch M (1982). Effects of dimethyl sufoxide on the globally ischemic heart: Possible general relevance to hypothermic organ preservation. Cryobiology 19:61-69.

Sekhar BC (2009). Cyclic 1,3-diones and their derivatives-As versatile reactive intermediates in the syntheses of condensed fused ring heterocyles. J. Heterocyclic Chem. 41(6):807-855.

Sheweita SA (2000). Drug-metabolizing enzymes: mechanisms and functions. Curr. Drug. Metab. 1(2):107-132.

Spasov AA, Yozhitsa IN, Bugaeva LI, Anisimova VA (1999). Benzimidazole derivatives: spectrum of pharamacolical activity and toxicol. properties (A review). Pharm. Chem. J. 33:232-243.

Spiteller G (1996). Enzymic lipid peroxidation- a consequence of cell injury? Free Radic. Biol. Med. 21:1003-1009.

Watanabe H, Kakihana M, Ohtsuka S, Sugishita Y (1998). Preventive effects of carvedilol on nitrate tolerance-A randomized, doubleblind, placebo-controlled comparative study between carvedilol and arotinolol. J. Am. Coll. Cardiol. 32:1201-1212.

Wu D, Cederbaum A (2006). Nitric oxide donors prevent while the nitric oxide synthase inhibitor LNAME increases archidonic acid plus CYP2E1-dependent toxicity. Toxicol. Appl. Pharmacol. 216(2):282292.

Zhang J, Knapton A, Lipshultz SE, Weaver JL, Herman EH (2008). Isoproterenol-induced cardiotoxicity in sprague-dawley rats: correlation of reversible and irreversible myocardial injury with release of cardiac troponin $\mathrm{T}$ and roles of iNOS in myocardial injury. Toxicol. Pathol. 36:277-278.

Zhou XZ, Vaziri ND, Zhang, Wang HW, Wang ZQ (2002). Association of renal injury with nitric oxide deficiency in aged SHR: Prevention by hypertension control with AT $_{1}$ blockade. Kidney Int. 62:914-921. 